\title{
O baile do monstro: \\ O mito da Paz de Vestfália na história das relações internacionais modernas
}

The Monster Ball:

The myth of the Peace of Westphalia in the history of modern international relations

Diego Santos Vieira de JESUS ${ }^{\bullet}$

\begin{abstract}
Resumo: O objetivo deste artigo é problematizar o mito da Paz de Vestfália nas relações internacionais modernas, trazendo interpretações alternativas para tal evento e para seus impactos no estudo da história das relações internacionais e nas relações internacionais contemporâneas. Problematizando, primeiramente o marco histórico, o argumento central aponta que a Paz de Vestfália não promoveu profunda inovação nem ruptura em relação à perspectiva anterior à Guerra dos Trinta Anos no que diz respeito aos aspectos essenciais das unidades constitutivas do Sacro Império Romano e das prerrogativas do imperador, apenas confirmou uma ordem cooperativa legal de entidades autônomas não-soberanas. O questionamento da existência empírica de um sistema inviolável de Estados soberanos evidencia, a seguir, as brechas nos princípios de autonomia e de territorialidade do modelo vestfaliano de relações internacionais. Finalmente, as interpretações alternativas do impacto da Paz de Vestfália para as relações internacionais e para seu estudo indicam que a igualdade formal entre os Estados intensifica dificuldades na resposta às diferenças na cultura, na religião e no modo de vida.
\end{abstract}

Palavras-chave: História das Relações Internacionais; Paz de Vestfália; Soberania.

Abstract: The aim of this article is to cast doubt on the myth of the Peace of Westphalia in modern international relations, bringing alternative interpretations for such an event and its impact on the study of the history of international relations and contemporary international relations. First, discussing the historical framework, the central argument points out that the Peace of Westphalia did not promote any important innovation or break-up in relation to the perspective before the Thirty Years' War regarding to the essential aspects of the constituent units of the Holy Roman Empire and the emperor's prerogatives confirming just a cooperative legal order from nonsovereign autonomous entities. The questioning to the empirical existence of an inviolable system of sovereign states shows the gaps in the principles of autonomy and territoriality of the Westphalian model of international relations. Finally, the alternative interpretations of the impact of the Peace of Westphalia on international relations and its study indicate that the formal equality among states intensify difficulties in the response to differences in culture, religion and ways of life. Keywords: History of International Relations; Peace of Westphalia; Sovereignty.

A Paz de Vestfália de 1648 refere-se a um conjunto de tratados que encerrou a Guerra dos Trinta Anos, iniciada com a intensificação da rivalidade política entre o Imperador Habsburgo do Sacro Império Romano-Germânico e as cidades-Estado luteranas e calvinistas no território do norte da atual Alemanha que se opunham ao seu controle. Tal guerra teve o envolvimento de potências católicas administradas pelos Habsburgo, como a Espanha e Áustria, e também de Estados protestantes escandinavos e da França, que, mesmo sendo católica, temia o domínio dos Habsburgo na Europa e apoiou os protestantes no conflito. Enquanto o tratado entre a Espanha e os Países

\footnotetext{
- Professor Doutor - Instituto de Relações Internacionais e Programa de Pós-Graduação em Relações Internacionais PUC-Rio - Pontifícia Universidade Católica - Rua Marquês de São Vicente, 225, CEP: 22451-900, Rio de Janeiro, RJ, Brasil. E-mail: dsvj1408@ terra.com.br
} 
Baixos - assinado em Münster, no mês de janeiro - pôs fim à Guerra dos Oitenta Anos, o tratado assinado em Osnabrück, em outubro, pelo Sacro Imperador Romano-Germânico Fernando III, pelos príncipes do Sacro Império Romano-Germânico, pela França e pela Suécia encerrou a luta dessas duas últimas potências com o Sacro Império. Nos estudos mais tradicionais sobre tal evento e da história das relações internacionais, concebe-se que a Paz de Vestfália, além de consolidar a independência dos Países Baixos, abalou o poder do Sacro Imperador, além de ter autorizado que os governantes dos estados germânicos gozassem a prerrogativa de estipular a religião oficial dos territórios sem interferência externa e oferecido reconhecimento legal aos calvinistas (WATSON, 1992, p.182-197).

Ao passo que a França firmava-se como a principal potência europeia e os Habsburgo viam sua ambição hegemônica ser tolhida após a Paz de Vestfália, os resultados daqueles acordos foram mais amplos para o estudo das relações internacionais modernas e contemporâneas. A Paz de Vestfália é concebida como um marco fundamental do sistema laico das interações e dos princípios estatais modernos, como a soberania territorial, a não-interferência na política doméstica dos demais Estados e a tolerância entre unidades políticas dotadas de direitos iguais. Como destaca Philpott (1999, p.567-569), Vestfália permitiu a constituição da sociedade internacional, com normas mutuamente acordadas que definem os detentores de autoridade e suas prerrogativas, sendo o Estado moderno essa autoridade detentora de soberania. O sistema de Estados soberanos exigia instituições estatais dentro das fronteiras e o desaparecimento de autoridades que interferissem de fora, para que a autoridade suprema vigorasse dentro do território e tivesse independência política e integridade territorial. Tal autoridade conota legitimidade - aqui entendida como o direito de controlar instituições e poderes - e territorialidade, num momento em que as pessoas governadas pelos detentores de soberania são definidas pela locação dentro das fronteiras, não por relações familiares ou por crença religiosa.

Nos termos mais tradicionais, a Paz de Vestfália é concebida na área de Relações Internacionais como uma revolução constitucional, pois, embora não tenham trazido uma metamorfose instantânea e as instituições políticas medievais ainda tenham permanecido por um bom tempo, tais tratados consolidaram o sistema moderno e trouxeram práticas subsequentes que definiram uma nova estrutura para a autoridade política. Ao estabelecer o Estado como entidade política legítima, o conceito principal de autonomia consolidou-se nas liberdades dadas às cidadesEstado alemãs em relação à interferência imperial. Naquele momento, a igualdade entre cidadesEstado europeias e a rejeição da autoridade universal papal e imperial apareciam frequentemente, enquanto os negociadores já vislumbravam um equilíbrio europeu, que pressupunha ação independente. Outro princípio consolidado foi o da não-intervenção: embora o Sacro Império Romano tenha continuado a existir, os príncipes podiam fazer alianças fora do Império, de forma a 
exercerem poder independente, e nem os príncipes nem o imperador intervieram para resolver questões religiosas no território de outro príncipe. Ademais, foram oferecidas garantias a novas unidades quanto à adesão ao sistema, desde que tivessem atributos como um governo viável, o controle do próprio território e a habilidade para fazer e honrar tratados. Com expansão colonial no século XIX e a descolonização afro-asiática do século XX, o sistema de Vestfália adquiriu uma abrangência maior, chegando também à periferia do planeta (PHILPOTT, 1999, p.579-584).

Nesse sentido, a Paz de Vestfália tornou-se um marco fundamental para os estudos das relações internacionais contemporâneas. Porém, como destaca Walker (2005, p.7), a construção de mitos de origem nas Relações Internacionais naturalizam uma interpretação específica e particular da história e recorrem ao universal construindo um regime sobre a "verdade" do sistema internacional com o objetivo de preservar os mecanismos de poder e de excluir interpretações e fenômenos alternativos, silenciando-se visões contrastantes e projetando aspectos do momento particular para outros tempos. Desafiando essa força de criação do mito da Paz de Vestáfilia, o objetivo deste artigo é problematizar tal mito nas relações internacionais modernas, trazendo interpretações alternativas para tal evento e para seus impactos no estudo da história das relações internacionais e nas relações internacionais contemporâneas. Problematizando primeiramente o marco histórico, o argumento central aponta que a Paz de Vestfália não promoveu profunda inovação nem ruptura em relação à perspectiva anterior à Guerra dos Trinta Anos quanto a aspectos essenciais das unidades constitutivas do Sacro Império Romano e das prerrogativas do imperador e apenas confirmou uma ordem cooperativa legal de entidades autônomas não-soberanas. $\mathrm{O}$ questionamento da existência empírica de um sistema inviolável de Estados soberanos evidencia, a seguir, as brechas nos princípios de autonomia e de territorialidade do modelo vestfaliano de relações internacionais. Finalmente, as interpretações alternativas do impacto da Paz de Vestfália para as relações internacionais e para seu estudo indicam que a igualdade formal entre os Estados intensifica dificuldades na resposta às diferenças na cultura, na religião e no modo de vida. As divisões do artigo cobrirão os passos indicados, e, na última seção, buscarei o desenvolvimento de um entendimento alternativo das fronteiras vestfalianas.

\section{A problematização do marco histórico}

A visão dominante na academia sobre a Paz de Vestfália aponta que o Sacro Império estava mais dividido em 1648 que antes de 1618 e que o papel do imperador foi reduzido com os tratados. A Guerra dos Trinta Anos teria sido conduzida contra a "ameaça trazida pelos Habsburgo", e Vestfália teria trazido maior enfoque à soberania e à “construção de ordem anti-hegemônica”. Nesse sentido, a Paz de Vetsfália representa o fim de uma luta entre as aspirações hierárquicas lideradas pelos Habsburgo na configuração da ordem internacional e as aspirações de surgimento de novos 
Estados. Porém, desestabilizando a versão mais tradicional, a perspectiva crítica assumida neste artigo permite observar que nenhum dos atores que lutaram contra Habsburgo foi à guerra por propósitos simplesmente defensivos em relação às supostas "ambições hegemônicas" da dinastia. Ao passo que a França e a Suécia desejavam a guerra para erodir a posição dos Habsburgo e a França visava a derrotar a Áustria para tomar a liderança dos Estados católicos, a Dinamarca temia que forças da Contrarreforma pudessem conquistar o território do norte da atual Alemanha antes dela. Ao contrário do que as versões mais tradicionais da história das relações internacionais do período defendem, os Habsburgo não representavam uma ameaça iminente a tais atores nem os haviam atacado em seus próprios territórios. Ademais, Vestfália não estabeleceu o "sistema vestfaliano" baseado no Estado soberano nem criou um protótipo do sistema internacional atual embasado na soberania, mas apenas confirmou a existência de uma ordem cooperativa legal de entidades autônomas não-soberanas (OSIANDER, 2001, p.270-273).

A visão mais típica acerca de Vestfália foi constituída e reproduzida por historiadores dos séculos XIX e XX, influenciados pela propaganda anti-Habsburgo. Porém, ela não leva em conta que nenhum dos tratados de 1648 tocou na questão da soberania nem faz menção aos seus corolários, como a não-intervenção, ou ao conteúdo positivo da soberania, particularmente as áreas sobre as quais o Estado pode comandar legitimamente. Vestfália não promoveu profunda inovação ou ruptura em relação às características das unidades constitutivas do Sacro Império e das prerrogativas do imperador, que eram em 1648 praticamente as mesmas que em 1618, além de que instituições do Sacro Império continuaram existindo, pois diversos atores as consideravam úteis. Alguns Estados menores, por exemplo, poderiam utilizá-las para efetuar o equilíbrio de poder em relação a membros maiores. Outras entidades políticas com controle exclusivo sobre um território bem definido existiam antes de Vestfália, como era o caso da Inglaterra, ao passo que instituições feudais e universais como o Sacro Império e o papado continuaram a existir depois. Nesse sentido, Vestfália não representou profunda ruptura com a ordem política anterior, num momento que parecia refletir muito mais os interesses de curto prazo dos poderes vitoriosos em vez de uma conceituação ampla das formas como o sistema internacional deveria ser ordenado (OSIANDER, 2001, p.260-268; KRASNER, 1993, 1996).

O que Vestfália fez, em certa medida, foi consagrar uma ordem cooperativa legal de entidades autônomas não-soberanas, o que indica que a soberania não é o único conceito ou forma possível de interpretar a interação entre atores autônomos. As unidades constitutivas do Sacro Império não eram sujeitas à autoridade centralizada, mas ao controle jurídico externo, de forma que o Sacro Império lembrava menos um Estado e mais um regime. O direito das unidades de concluir alianças com atores estrangeiros existia antes de Vestfália. Além disso, a condição de ator nas relações internacionais era baseada menos no poder militar e mais na convenção mútua, num momento em 
que as unidades constitutivas do império, bem como a entidade coletiva que constituíam, existiram por causa do "empowerment" mútuo e coletivo, sustentado por um código compartilhado de legitimidade estrutural e procedimental. Assim, em vez de pensarem exclusivamente no autointeresse, tais unidades demonstravam um volume considerável de "comportamento social", e o nível de autonomia dos atores pode variar consideravelmente - em parte por sua própria escolha -, sem necessariamente levar à dominação hegemônica. Diante do elevado nível de ligação transfronteiriça entre tais unidades, formas mais sofisticadas de cooperação institucionalizada foram sendo elaboradas (OSIANDER, 2001, p.270-284).

Abalizado numa perspectiva histórica dinâmica, cumulativa e retrospectivamente inteligível não teleológica - da interação entre estruturas de propriedade e práticas antagônicas transformadoras das relações sociais, Teschke (2003) desvela mecanismos generativos e transformativos das ordens geopolíticas internacionais ao explicar suas diferenças institucionais e dinâmica de transição, com base nas estratégias de reprodução de classe: mais do que fenômenos econômicos, as relações sociais de propriedade são uma práxis social, que, ao mediar relações intra e interclassistas, constitui unidades da ordem geopolítica, que operarão a mudança desse sistema. Os confrontos temporalmente específicos entre forças sociais cristalizam-se em instituições condicionantes de estratégias antagônicas de reprodução de relações historicamente particulares entre e dentro de classes, fixando regimes de propriedade politicamente construídos e conflitos sociais que orientam a mudança e constituem interações determinantes da operação das ordens geopolíticas.

A partir do questionamento da direção temática e legitimidade histórica do mito de Vestfália como base da interação estatal moderna, o autor aponta que é possível problematizar concepções estáticas e deterministas da ordem e, num entendimento dialético do desenvolvimento histórico, mudar o enfoque dos mecanismos sistêmicos de estruturação da ordem para uma interpretação crítica que elucida relações sociais sustentadoras da ordem vestfaliana e a interdependência das constituições do econômico/político e doméstico/internacional pelas relações de propriedade. Nessa perspectiva, a Paz de Vestfália, em vez de inaugurar relações interestatais modernas, somente reconhece um sistema germânico de interação não-moderna entre unidades miniabsolutistas plurais não-secularizadas, embasado em relações de propriedade social pré-capitalista, e cristaliza o status quo territorial e legal favorável aos vencedores da Guerra dos Trinta Anos. A juridificação da política continental dinástica com referência nos Estados germânicos objetivava a manutenção de paz, não a conquista de autodeterminação (TESCHKE, 2003). 


\section{As brechas nos princípios de territorialidade e de autonomia}

As leituras mais tradicionais sobre a Paz de Vestfália na história das relações internacionais apontam que o modelo vestfaliano de sociedade internacional que se estende até os dias atuais é um sistema de autoridade política caracterizado pelos princípios de autonomia e de território. Porém, a leitura crítica proposta neste artigo sinaliza que, ao contrário do que sugere tal concepção mais tradicional, o modelo vestfaliano não foi um equilíbrio estável ao longo da História, de forma que os Estados frequentemente tiveram incentivo e poder para violá-lo ou para abrir brechas em seus princípios. De acordo com Krasner (1996, p.123-140), a brechas no modelo vestfaliano de uma soberania inviolável ficam visíveis nas convenções internacionais, acordos nos quais os Estados fazem compromissos que expõem suas próprias políticas a algum tipo de escrutínio externo ao concordarem em seguir certas práticas domésticas. Além disso, com a coerção, os Estados ameaçam impor sanções a menos que as contrapartes comprometam sua autonomia doméstica, e o alvo pode obedecer ou resistir. No caso da imposição, os Estados-alvo são tão fracos, que devem aceitar estruturas e políticas domésticas preferidas por atores poderosos, pois, caso contrário, serão eliminados.

Os contratos e as convenções internacionais jamais violam a definição do direito internacional para soberania - o direito de certos atores a aderir a acordos internacionais -, mas podem violar o modelo vestfaliano se comprometerem a autonomia do Estado. A coerção e a imposição pode violar tanto a concepção de soberania do direito internacional como o modelo vestfaliano. Esses mecanismos deixam pelo menos um ator com prejuízos. Cumpre lembrar que "comprometer" Vestfália foi, algumas vezes, visto como a melhor forma de se alcançar a paz e a estabilidade. Segundo Krasner (1996, p.140-149), os principais tratados e acordos de paz - incluindo a própria Paz de Vestfália - incluíram violações ao modelo vestfaliano, principalmente ao princípio da autonomia. As infrações ao modelo de Vestfália não foram encobertas ou não-explicadas; ao contrário, foram justificadas por princípios alternativos como os direitos humanos, os direitos das minorias, a responsabilidade fiscal, a estabilidade doméstica ou o equilíbrio externo até a contemporaneidade.

Nesse sentido, a ordem vestfaliana pautada nos princípios de autonomia e territorialidade caracterizada pela independência política dos Estados e pela não-intervenção nos assuntos domésticos uns dos outros - foi, ao longo da História, constantemente comprometida em face da atração dos Estados pela adesão a princípios alternativos que permitiriam a satisfação dos seus interesses, bem como a consolidação das assimetrias de poder. Krasner (1996, p.150-151) destaca que, como não existe no sistema internacional uma autoridade suprema capaz de controlar ou de impedir as ações desses Estados, tais atores tiveram o incentivo e a oportunidade para violar princípios de autonomia e de independência de ação de acordo com os seus interesses - muitas 
vezes aderindo a princípios alternativos com o objetivo de maximizar seus ganhos e preservar a estabilidade da ordem global - e seu poder.

Além disso, os princípios de territorialidade e de autonomia e as brechas abertas nesses princípios pela atração por princípios alternativos não estão dados ou fixos. Ao contrário, eles podem ser vistos como resultados de processos complexos de construção da identidade estatal. Transcendendo a visão de simples instrumentalização da cultura na busca de satisfação de interesses materiais pelos Estados e desvelando a dinâmica cultural constitutiva de identidades e interesses na formação dessas comunidades políticas, Rae (2002) explica a resistência de procedimentos sistemáticos de homogeneização patológica de constituição estatal com base na relevância da manipulação temporal e espacialmente específica de recursos simbólicos disponíveis para elites. Tais elites visam à construção da identidade coletiva estatal pela exclusão sistemática da diferença e à legitimação de sua autoridade nas fronteiras dessa comunidade política unificada. A construção da identidade corporativa interna é mutuamente constitutiva da identidade social externa do Estado, de forma que as práticas excludentes domésticas levaram ao desenvolvimento de normas internacionais de comportamento legítimo que as proscrevem e têm efeito na construção dessa identidade corporativa. A identidade social do Estado pode operar como constrangimento externo a mecanismos patológicos de homogeneização oferecendo alternativas de legitimação do poder, embora algumas vezes possa ser insuficiente para a reconstituição de estruturas normativas internas que apontem para noções menos exclusivistas de cidadania, garantindo-se os pré-requisitos para a permanência da violência na relação com a diferença.

Com o enfoque na definição de fronteiras políticas a partir de práticas internas de homogeneização, Rae (2002) ilumina a operação do processo disciplinador da subjetividade baseado na manipulação e reprodução de referenciais simbólicos, em que os métodos para a definição do Estado, como ordem normativa central, viabilizam a identificação ao autorizar o tratamento discriminatório dos outsiders. Torna-se patente a multiplicidade de estratégias excludentes empregadas pelas elites construtoras do Estado para conquista da homogeneização populacional e a legitimação de autoridade, desde políticas de assimilação até práticas refinadas de extermínio e expulsão. A criação do "outro" como categoria social compõe um procedimento político de tradução espaço-temporal da diversidade como ameaça e de expulsão e aniquilação dessa diferença objetivada pelas elites, buscando preservar a unidade soberana. A autora desestabiliza a fronteira analítica entre interno e externo, compreendendo que a dinâmica política nos contornos da entidade soberana não está desconexa da política internacional: a manipulação simbólica continua atrativa para legitimar regimes, mas a proteção de cidadãos em relação a seus governos torna-se preocupação transterritorial, fortalecendo atritos entre a não-intervenção e a defesa de princípios universais como os direitos humanos no mundo contemporâneo. 


\section{A Paz de Vestfália e o problema da diferença}

Além de desestabilizar o marco histórico e o modelo vestfaliano, é também possível desenvolver interpretações alternativas do impacto da Paz de Vestfália para as relações internacionais e para seu estudo. Ao contrário do que propõem as interpretações tradicionais sobre o evento, Blaney e Inayatullah (2000, p.33-44; 2004, p.93-125) apontam que, embora Vestfália seja entendida convencionalmente como um marco na transição para uma ordem mais secular e tolerante, os arranjos institucionais desenvolvidos naquele momento serviram para assegurar a persistência e a centralidade do problema da diferença na sociedade internacional. Num momento em que a Guerra dos Trinta Anos tinha representado uma cruzada contra a diferença, envolvido a equação entre diferença e inferioridade e operado como a culminação inevitável de um longo período em que a diferença era traduzida como um objeto a ser erradicado. A Paz de Vestfália parecia, à primeira vista, uma resposta à limpeza religiosa e à devastação material e psicológica da Guerra dos Trinta Anos. Porém, embora tenha levado a uma détente externa entre as unidades políticas no Sacro Império, Vestfália fez pouco para romper a concepção e a prática de delineação da diferença como uma inferioridade a ser erradicada. Ao contrário, a veneração que a área de Relações Internacionais ofereceu à Vestfália tendeu a desviar a atenção de respostas criativas à diferença que foram perdidas durante o período, bem como esvair a tarefa de explorar a fonte das chagas na resposta dominante à diferença e à análise das maneiras em que o discurso intelectual reforçou, em vez de desafiar, a interpretação da diferença como uma aberração perigosa das normas de estabilidade, segurança e ordem.

A releitura crítica de Vestfália por Blaney e Inayatullah (2000, 2004) viabiliza a problematização de tal evento visto tradicionalmente como um marco de transição para uma modernidade mais tolerante e oferece uma ênfase à influência deletéria da Guerra dos Trinta Anos no discurso intelectual sobre a diferença, administrada a partir de estratégias espaciais de segmentação. Na prática, em vez de resolver o problema da diferença religiosa, Vestfália manteve vivos os conflitos religiosos, perpetuando as divisões religiosas, mas numa forma contida. Apesar da defesa da liberdade religiosa, as limitações morais colocadas sobre líderes entravam em conflito com direito soberano de ditar a fé do reino. $\mathrm{O}$ efeito disso foi a divisão da Europa em espaços católicos e protestantes, dentro dos quais minorias não-conformadas continuavam sendo problema. Nesse sentido, a segmentação entre "dentro" e "fora" constitutiva da "sociedade de Estados" - que consolida as delimitações geopolíticas como receptáculos espaciais da diversidade cultural e nos mantém reféns do entendimento depreciativo da diferença - opera como pré-requisito para o adiamento do "problema da diferença" e a diluição de oportunidades para maior engajamento com a diversidade. Tal quadro decorre das implicações práticas e intelectuais da homogeneização cultural sistemática e da constituição uniformizadora das novas unidades políticas, que realoca o 
"problema" para a dimensão doméstica - onde se esperava que a diversidade fosse administrada - e perpetua a violência com relação às minorias não-conformadas à "fé nacional" dentro dessas unidades (BLANEY; INAYATULLAH, 2004, p.44-45).

A tolerância entre elas procede do equilíbrio de poder e não do reconhecimento genuíno da diversidade, consolidando-se a noção de que a construção de uma "diferença internacionalizada" poderia resolver o "problema" ao se negociarem regras para o relacionamento entre comunidades políticas. Porém, tal procedimento restringe o reconhecimento dos "Outros internos" e a apreciação do Eu como parte do Outro além das fronteiras. A resposta hierarquizante e disciplinadora à diferença domesticamente transborda para seu tratamento na esfera externa: entendida como elemento desestabilizador da harmonia doméstica, a diferença interna é gerenciada com hierarquia, erradicação, assimilação ou expulsão, enquanto a externa é vista como ameaça constante interditada nas fronteiras, enfrentada militarmente ou colonizada. Naquele contexto, em resposta às guerras religiosas e aos desafios na incorporação dos ameríndios às visões de mundo europeias, o legado intelectual do momento naturaliza a diferença como elemento desestabilizador da associação política unificada e harmoniosa. Pensadores modernos inseridos em empreendimentos de pacificação buscavam fundações não-questionáveis da autoridade soberana e desproviam o "estado de natureza" da riqueza da sociedade civil. Nessa ocasião, a classificação dos ameríndios num estágio pré-social associado à desordem - o "estado de natureza" - procurava resguardar a noção de "superioridade cultural" europeia e fortalecer a justificativa de práticas coloniais. Em vez de apoiar a abertura em relação ao Outro, o legado intelectual da época carrega uma suspeita intensa em relação à diferença, vista como causa da desordem, enquanto a uniformidade e a homogeneidade eram associadas à ordem social e à estabilidade (BLANEY; INAYATULLAH, 2004, p.93-125). Porém, Blaney e Inayatullah (2004) vislumbram que a ambiguidade na caracterização da diferença como fonte de desordem, mas também como de desejo sugere a possibilidade de entendimentos ético-políticos alternativos na "zona de contato" com tal diferença. Essa "selvageria" era uma possibilidade em cada ser humano e, além de perigo, representava desejo. Tem-se, assim, "elementos de improviso" que explicitam possibilidades de engajamento com a diferença, permitindo reconhecer elementos de contato e fortalecer elementos de redenção.

\section{Por um entendimento alternativo das fronteiras vestfalianas}

A partir do questionamento do marco histórico da Paz de Vestfália, da evidência de brechas no modelo vestfaliano de ordem internacional e da crítica à marginalização da diferença que tais fronteiras vestfalianas promoveram, é possível esclarecer não apenas as relações de poder evidentes no conhecimento produzido sobre o mito de Vestfália na história das relações internacionais, mas buscar alternativas na forma de pensarmos e entendermos as fronteiras, inicialmente erguidas pelo 
discurso da soberania. Problematizando a aceitação de limites territoriais cristalizados e naturalizados, Williams (2006) salienta que as fronteiras territoriais podem ser concebidas como eticamente fundamentais na expressão e na preservação da diversidade na política internacional e operar como mecanismos de sustentação da tolerância à diferença. Seria fundamental, assim, repensar as fronteiras com base no seu significado ético como práticas sociais. Isso permitiria ressaltar o papel da agência humana e possibilitaria a articulação arendtiana da pluralidade essencial a uma leitura distinta da ética global de tolerância: vendo na promessa e no perdão as orientações para a superação dos erros passados, concebe-se um "espaço intermediário" de intersubjetividade no qual se viabilizam a constituição da identidade com o engajamento com a diferença e o compartilhamento de valores por meio da interação social (WILLIAMS, 2006).

A partir das concepções de antecedência da diversidade em relação à soberania e de simbiose entre ambos, o tratamento complexo das fronteiras territoriais constrói-se a partir da problematização do conceito vestfaliano de soberania. Questionando noções reificadoras de “fronteiras como cercas", podemos buscar ferramentas metodológicas e analíticas para a elucidação do papel intrinsecamente ético desses limites sem menosprezar a força da soberania como norma constitutiva da sociedade internacional: tais fronteiras são entendidas como resultado de práticas sociais que podem existir independentemente da soberania, e a soberania é compreendida como uma resposta provisória e dinâmica - não imutável e essencializada - aos desafios trazidos pela diversidade, demarcando espaços políticos que permitem a constituição de comunidades distintas e a delimitação de valores plurais com potencial imanente de mudança. Ao estabelecer uma conexão entre a redefinição crítica das fronteiras territoriais pela geografia política pós-positivista e a investigação de questões ético-normativas nas Relações Internacionais, Williams apreende o instrumental teórico de Hannah Arendt para a investigação da relevância ética das fronteiras territoriais na preservação da diversidade, retornando-as ao "mundo político" a partir da defensibilidade ética no seu tratamento como práticas sociais e permitindo escapar ao seu confinamento a conceitos essencializados, como a noção dominante de soberania vestfaliana. Concebendo que o autoconhecimento é fundamental para o reconhecimento da diferença, seus méritos abalizam-se na exploração da conexão da pluralidade à comunidade, no reconhecimento da condição humana aos demais indivíduos e na compreensão da política - distinta da burocratização do aparato administrativo que restringe o envolvimento político das massas - como a forma maior de atividade humana, em que são desenvolvidas oportunidades de constituição da identidade e das noções de pertencimento no engajamento dinâmico e flexível com a diversidade num contexto de entendimentos compartilhados, produzidos numa interação social que não implica aniquilação ou padronização da pluralidade dentro de comunidades ou entre elas. 
A defesa da pluralidade como imperativo ético transcende a constituição homogeneizante do pluralismo pelas noções reificadoras de identidade comunal e focadas no Estado - como o nacionalismo - e significados políticos universalizantes: o direito de pertencer a comunidades políticas assegura sentido e efetividade à posse de direitos - o "direito de ter direitos" - e reafirma a pluralidade dos indivíduos, negada por projetos totalitários que os submetem à "solidão" ao desarticularem sua capacidade de se relacionar com os outros. Ao estabelecerem "espaços discursivos intermediários" de reconhecimento e engajamento com a diversidade, as fronteiras podem ajudar a compor a pluralidade das comunidades humanas pela distinção entre elas em base territorial, e a violência da intolerância - politicamente nula - representa uma ameaça ao espaço político ao destruir os sentidos da promessa e do perdão. No sentido da superação do simples significado ético derivativo dessas fronteiras, poderíamos caminhar rumo à defesa ética positiva, que examina a relevância das práticas sociais de criação de fronteiras territoriais na manutenção da convivência e do engajamento, genuínos à diversidade, e dos diferentes níveis de acomodação da diferença no sistema político. A criação dos "espaços intermediários" nos quais a ação política se processa a partir do entendimento e diálogo viabilizaria a desreificação e a repolitização das fronteiras, encorajando maior riqueza nas concepções de pluralismo e pluralidade a partir do envolvimento político entre indivíduos e comunidades reais, não de conceitos abstratos como uma "imensa coletividade humana" ou de práticas elitistas de interação diplomática. Porém, até o momento, ainda somos, na visão de Blaney e Inayatullah (2000), reféns dos tipos de impulso em relação à diferença que marcaram a Guerra dos Trinta Anos, num momento em que continuamos com o entendimento da diferença como desordem e falhamos na apreciação de oportunidades e de recursos que acompanham o engajamento com o Outro dentro e fora das fronteiras. Enquanto ainda continuamos vendo simplesmente monstros que nos atormentam, perdemos oportunidades de entender a complexidade dos universos por trás dessas máscaras que dançam.

\section{Referências bibliográficas:}

BLANEY, D.; INAYATULLAH, N. The Westphalian deferral. International Studies Review, v.2, n.2, p.29-64, 2000.

International Relations and the problem of difference. Nova York: Routledge, 2004.

OSIANDER, A. Sovereignty, International Relations, and the Westphalian myth. International Organization, v.55, n.2, p.251-287, primavera 2001.

KRASNER, S.D. Westphalia and all that. In: GOLDSTEIN, J.; KEOHANE, R. (Eds.) Ideas and foreign policy: beliefs, institutions and political change. Ithaca, Londres: Cornell University Press, 1993. p.235-264. 
Compromising Westphalia. International Security, v.20, p.115-151, 1995-1996.

PHILPOTT, D. Westphalia, authority, and international society. Political Studies, v.XLVII, n.3, p.566-589, 1999.

RAE, H. State identities and the homogenisation of peoples. Cambridge: Cambridge University Press, 2002.

TESCHKE, B. The myth of 1648: class, geopolitics, and the making of modern international relations. Londres; Nova York: Verso, 2003.

WALKER, R.B.J. The doubled outsides of the Modern International. 5th International Conference on Diversity in Organizations, Communities and Nations. C.a.N. Fifth International Conference on Diversity in Organizations. Beijing, 2005.

WATSON, A. The evolution of international society: a comparative historical analysis. Londres, Nova York: Routledge, 1992.

WILLIAMS, J. The ethics of territorial borders: drawing lines in the shifting sand. Houndmills, Basingstoke, Hampshire; Nova York: Palgrave Macmillan, 2006. 